\title{
Characterization of Atmospheric Reactive Nitrogen Emissions from Global Agricultural Soils
}

\author{
Viney P. Aneja *, William H Schlesinger, Qi Li, Alberth Nahas and William H. Battye \\ 1 Department of Marine, Earth, and Atmospheric Sciences, North Carolina State University, Raleigh, NC \\ 27695-8208, USA \\ 2 Cary Institute of Ecosystem Studies, Millbrook, NY 12545, USA \\ * Correspondence: vpaneja@ncsu.edu
}

\begin{abstract}
Global nitric oxide (NO) emissions into the atmosphere are projected to increase in the coming years with the increased use of synthetic nitrogen fertilizers and fossil fuel combustion. Here; a statistical model (NO_STAT) is developed for characterizing atmospheric NO emissions from agricultural soil sources; and compared to the performance of other global and regional NO models (e.g., EDGAR and U.S. EPA). The statistical model was developed by developing a multiple linear regression between $\mathrm{NO}$ emission and the physicochemical variables. The model was evaluated for $2012 \mathrm{NO}$ emissions. The results indicate that, in comparison to other data sets; the model provides a lower global NO estimate by 59\%, (NO_STAT: $0.67 \mathrm{Tg} \mathrm{N}$ yr-1; EDGAR: $1.62 \mathrm{Tg} \mathrm{N}$ yr-1). We also performed a region-based analysis (U.S., India; and China) using the NO_STAT model. For the U.S., our model produces an estimate that is $47 \%$ lower in comparison to EDGAR. Meanwhile; the NO_STAT model estimate for India shows NO emissions $75 \%$ lower when compared to other data sets. A lower estimate is also seen for China; where the model estimates NO emissions $82 \%$ lower than other data sets. The difference in the global estimates is attributed to the lower estimates in major agricultural countries like China and India. The statistical model captures the spatial distribution of global $\mathrm{NO}$ emissions by utilizing a more simplified approach than those used previously. Moreover; the NO_STAT model provides an opportunity to predict future NO emissions in a changing world.
\end{abstract}

Keywords: global; nitrogen oxides emissions; agricultural soils; predict future nitrogen oxides emissions from agricultural soils; statistical model

\section{Introduction}

Nitrogen oxides $\left(\mathrm{NO} \times \mathrm{x}=\mathrm{NO}+\mathrm{NO}_{2}\right)$ are important trace constituents in the troposphere where they regulate the production and consumption of photochemical oxidants, ozone $\left(\mathrm{O}_{3}\right)$ and hydroxyl radicals (Warneck, 2000). Although these gases do not directly affect radiative balance, the formation of ozone and aerosols in the troposphere can result in negative consequences for air quality and the chemistry of the atmosphere. Numerous air pollution problems are caused by $\mathrm{NO}_{x}$ through chemical reactions--e.g. smog and acid rain. $\mathrm{NO}_{2}$, a form of $\mathrm{NO}_{x}$ in the atmosphere, has been listed as a criteria air pollutant by U.S. Environmental Protection Agency (U.S. EPA). In the National Ambient Air Quality Standards (NAAQS), the primary and secondary standard for $\mathrm{NO}_{2}$ is 53 parts per billion (ppb) annual average.

Tropospheric $\mathrm{O}_{3}$ is a significant air pollution problem in the United States, as well as in most developing countries. It is harmful to both human health and welfare. $\mathrm{NO}_{x}$ is an important precursor of tropospheric ozone formation. $\mathrm{NO}_{2}$ reacts in sunlight air to produce $\mathrm{NO}$. When $\mathrm{NO}$ concentration is below 3-8 ppt, $\mathrm{NO}$ reacts with $\mathrm{O}_{3}$ to produce $\mathrm{NO}_{2}$ and $\mathrm{O}_{2}$ thus consuming $\mathrm{O}_{3}$, but when $\mathrm{NO}$ 
concentration is higher, $\mathrm{NO}$ catalyzes the oxidation of $\mathrm{CH}_{4}, \mathrm{CO}$ and volatile organic compounds (VOC) to produce $\mathrm{O}_{3}$ (Warneck, 2000), and $\mathrm{NO}$ gets recycled to $\mathrm{NO}_{2}$ by free radicals. In rural environments, the reaction of NO with biogenic VOC can be a predominant source of ozone (Aneja et al., 1996). $\mathrm{NO}_{x}$ in the troposphere can be captured by moisture to form of nitric acid $\left(\mathrm{HNO}_{3}\right)$, a source of acid rain, which directly accelerates acidification and eutrophication processes in regional ecosystems.

$\mathrm{NO}_{x}$ can come from both natural sources, such as lightning, soil microbial activities and biomass burning, as well as anthropogenic sources such as soil fertilizer application and fossil fuel combustion (Aneja et al., 2008; Aneja et al., 2009; Schlesinger and Bernhardt, 2013; Bray et al., 2019; Houlton et al., 2019). Fossil fuel combustion contributes more than half of the global NO budget. Soils, especially agricultural soils, are a source of biogenic NO emissions. The estimate of global NO emission from cultivated soils is $\sim 16 \%$ of the total global NO budget ( $35 \mathrm{Tg} \mathrm{N} \mathrm{yr}^{-1}$ ) (Davidson and Kingerlee, 1997). Published field measurements and inventories show substantial NO emissions from tropical savannas (Poth et al 1995), successional pastures (Keller and Reiners, 1994), and intensively managed agriculture (Valente and Thornton, 1993; Aneja et al., 1996, 1998).

Many factors affect the $\mathrm{NO}$ emission from soil, e.g. soil temperature, soil $\mathrm{pH}$, soil moisture, as well as N availability in the soil (Sullivan et al., 1996). Pilegaard (2013) suggests that an important factor that affects NO emission is the availability of nitrogen in the soil, where it is derived from nitrogen fixation, nitrogen deposition, or inputs such as fertilizer and manure. In agricultural soils, $\mathrm{NO}$ emission is most affected by the available nitrogen from fertilizer and manure. Soil water content controls the rate of $\mathrm{O}_{2}$ supply, which directly affects the nitrification and denitrification (Battye et al., 2017). Goldberg \& Gebauer (2009) observed that NO emission decreased after precipitation, but increased during drought. In addition, due to the positive effect of soil temperature on microbial processes, NO emission generally increases with soil temperature (Schindlbacher et al., 2003). Although there is no direct relationship between the rate of $\mathrm{NO}$ emission and soil $\mathrm{pH}$, nitrification process are intensified at high soil $\mathrm{pH}$.

Uncertainties in the current global and regional estimates for $\mathrm{NO}$ emission still exist, so the estimates show a great range between the lowest and highest values. Also, most measurements are short-term and inherently do not represent the spatial and temporal variation of NO emission. This necessitates the use of field data and statistical models, ideally with few input parameters, to estimate NO emission from agricultural soil.

The goal of this study is to develop a statistical model to predict NO emissions from agricultural soils amended with synthetic and organic fertilizers using physicochemical properties of the soils from different regions. We also analyze the spatial distribution of $\mathrm{NO}$ emissions from agricultural soils and compare the results with a modeled emission inventory from EDGAR v.4.3.2.

\section{Materials and Methods}

Figure 1 displays the methodology we adopted to estimate $\mathrm{NO}$ global emissions from agricultural soil. We conducted a literature review in two parts. The initial review was intended to look for information on the physico-chemical variables controlling the $\mathrm{NO}$ emissions. Based on the initial literature review, we identified four variables which are readily available and which would be expected to be of importance in controlling NO emissions from soil: (1) soil moisture content, (2) soil temperature, (3) synthetic and organic fertilizer usage i.e. $\mathrm{N}$ content of soils, and (4) soil $\mathrm{pH}$. Meanwhile, a comprehensive literature review was conducted to gather results from field experiments to develop our model (NO_STAT). More on this is discussed in Section 2.1.

We performed a series of statistical analyses utilizing the $\mathrm{R}$ studio statistical software (https://github.com/rstudio/rstudio) to examine the distribution of data and to fit an appropriate regression model with $\mathrm{NO}$ as the response (dependent) variable and other variables as independent predictors. Lastly, we used Integrated Land and Water Information System (ILWIS) v.3.31 Academic (https://www.itc.nl/ilwis/download/ilwis33/), a GIS tool to prepare the global data sets and apply the statistical model for predicting NO emissions. 
The 3rd International Electronic Conference on Atmospheric Sciences (ECAS 2020), 16-30 November 2020; Sciforum Electronic Conference Series, Vol. 3, 2020

\subsection{Data collection}

Data collection includes two parts, (1) data sets for developing the statistical model (Table 1a), and (2) global data sets for extrapolating the results to larger areas (Table 1b). For the statistical model, we conducted a comprehensive literature review regarding NO emissions from agricultural soil. In our statistical model development, we have used results published principally after 1990 . We collected 94 sets of data to develop our model. In order to be included in the model, these datasets had to provide all variables listed in Table 1a. These datasets are the results from field experiments conducted in North America and western Europe. These datasets are supplemented by field results from China and India, as well as additional results from North America and Europe. Results reported in these papers were obtained from field experiments conducted at different times. However, our statistical model is designed to be independent of time, as reflected by the equation shown in the next section. Our model explores the measured physico-chemical variables of the agricultural soils as the inputs of the equation to determine the NO emissions empirically.

Prior to using these data, we synchronized the units for all parameters by converting them into the units summarized in Table 1a. This is particularly important for $\mathrm{NO}$ emissions and N inputs from fertilizer and manure, as the values given in the literatures were reported using different units. The complete data set used in this analysis is compiled in Table S. For the parameters in Table 1b, soil temperature and soil moisture are based on the year 2012. The original maps for cropland and manure fractions are based on the year 2000; however, these maps were adjusted by accounting for the changes in fertilizer inputs and cropland area between 2000 and 2012 using the FAO global fertilizer data for both years. The only parameter that was not based on 2012 is soil $\mathrm{pH}$, because there is no global map of soil $\mathrm{pH}$ available for that particular year.

\subsection{Model setup}

Based on the statistical analysis, we found that the data distribution, shown as the histogram of NO emissions (Figure 2a), was skewed to the right. To normalize the data, we transformed the data to the logarithmic value (Figure $2 b$ ), for which the data of $\log (\mathrm{NO})$ appears as a normal distribution. Most data are located between -2 and 2. Therefore, we assume the data are normally distributed.

Then, we used a multiple linear regression model to fit the response variable (the log of NO emissions), using the physicochemical variables as predictors. The statistically-derived model (hereinafter: NO_STAT) to predict NO emissions from agricultural soils is mathematically expressed as the following:

$$
\text { NO emission }=\left(\exp \left[A+B \times T_{\text {soil }}+C \times S M+D \times p H_{\text {soil }}+E \times \log (N \text { input })+F \times \text { Fertilizer type }\right]\right) \times \frac{14}{30}
$$

Where, Tsoil refers to soil temperature $\left({ }^{\circ} \mathrm{C}\right)$, SM soil moisture $(\%)$, and the coefficients A, B, C, $\mathrm{D}, \mathrm{E}$, and $\mathrm{F}$ are statistically-derived parameters (Table 2). Table 2 summarizes the coefficients and $\mathrm{p}$ values of each variable. Based on the $\mathrm{p}$-value, the soil moisture, soil $\mathrm{pH}$, fertilizer usage and fertilizer type are statistically significant. The Residual standard error is 1.57 , and R-squared is 0.38 . F-test shows that this multivariate linear regression model is statistically significant ( $90 \%$ confidence level), but notably, the magnitude of nitrogen input does not have a significant influence on the NO emission rate. This may seem counterintuitive, because $\mathrm{NO}$ emissions are produced by the microbial processes of nitrification and denitrification. Nitrogen concentrations may be the limiting factor in these reactions when the levels of soil nitrogen are low; however, other factors may become limiting when soil nitrogen concentrations are at agronomic levels (Aneja et al., 2019; Aneja et al., 2020).

\subsection{Model diagnostics}

After performing the regression analysis, we verified that NO_STAT works well for fitting the data and complies with the assumptions of linear regression. Figure $3 a$ and $3 b$ collectively give the results of the model diagnostics. A two-step model diagnostic was performed by analyzing the 
variance and distribution of the residuals. The QQ plot shown in Figure 3a is used to verify if the data used in developing the model are normally distributed. This plot shows that most of the data follow a straight line, suggesting that these data have a normal distribution. Meanwhile, the equal distribution with no distinct patterns of residuals around the horizontal (Figure $4 \mathrm{~b}$ ) provides a good indication of the likelihood of a linear relationship. Additionally, the majority of standardized residuals are clustered between -1 and 1 , also suggesting that the data are normally distributed. The outliers indicated by residuals that are far away from the line were excluded in further analysis.

\subsection{Dataset}

EDGAR: The Emission Database for Global Atmospheric Research compiles anthropogenic global NO emissions and trends from 1970 to 2012 based on international statistics and emission factors (Janssens-Maenhout et al. 2017). For NOx, we use the 2012 global data set for agriculture sectors (subsector $4 \mathrm{~B}+4 \mathrm{C}+4 \mathrm{D}+4 \mathrm{~F}$ ), which includes Enteric fermentation, Manure management, Rice cultivation, and Agricultural soils.

\section{Results}

The $\mathrm{NO}_{2}$ emission from agricultural soil is negligible, so this paper focuses on the emission of NO. After calculating the coefficients of all variables, we applied the NO_STAT model for each grid cell ( 5 arc-minute $x 5$ arc-minute) to generate a global map for $\mathrm{NO}$ emissions. Figure 4(a) gives the spatial distribution of global NO emission from agricultural soils calculated using NO_STAT in $\mathrm{kg} \mathrm{N}$ $\mathrm{yr}-1$ grid cell-1. The resolution of this map is 5 arc-minute, which is equivalent to 8464 ha. Figure 4(b) presents the spatial distribution of global NO emission from agricultural soil based on EDGAR. Total annual global NO emissions from NO_STAT and EDGAR are $0.671 \mathrm{Tg} \mathrm{N} \mathrm{yr}^{-1}$ and $1.623 \mathrm{Tg} \mathrm{N} \mathrm{yr} \mathrm{rr}^{-1}$, respectively. Based on these two values, the NO_STAT model gives a lower global NOx estimate by $59 \%$. However, it is important to note that our model only accounts for the NO emissions from agricultural soils, which is one of various factors considered in EDGAR. For the regional emissions, our model also gives NO emission estimates that are lower than EDGAR. Our model estimate for the continental U.S., China, and India are $-47 \%,-82 \%$, and $-75 \%$ lower than from EDGAR, respectively.

As discussed previously, our lower values may be attributed to other sources that are excluded in our model. EDGAR included additional sources in the estimate, e.g. Enteric fermentation, Manure management, and Rice cultivation. However, NO_STAT is exclusive to emissions from agricultural soils to which fertilizer and manure are applied as fertilizer. EDGAR and other inventories generally treat $\mathrm{NO}$ emissions as directly proportional to the amount of nitrogen added to soils in the form of fertilizer and animal waste. Our model suggests that, for agricultural soils, other parameters such as soil moisture and temperature may have a larger impact on nitrogen emissions than the amount of waste or fertilizer applied. Nevertheless, in general, the model shows a similar global spatial pattern in NO emissions. The hot spots show most NO emission comes from northern China, northern India, and the Mid-West U.S.

Our approach is subject to uncertainty. In particular, our statistical analysis was restricted to parameters that were available in the literature and in global data bases. Thus, the analysis did not include parameters such as soil composition and porosity, which could also influence NO emissions. We also do not take into account short term variations in moisture and temperature which may result in enhanced NO emissions. Further, data were not available to systematically incorporate differences in agricultural practices, such as the cultivation of more than one crop per year or the use of multiple fertilizer applications in a year.

Nevertheless, previous NO emissions inventory approaches are also subject to large uncertainties. Based on a literature survey, Hudman et al. (2012) used a mechanistic model of global soil $\mathrm{NO}$ emissions to estimate that total global $\mathrm{NO}$ emission from soil are $10.7 \mathrm{Tg} \mathrm{N} \mathrm{yr}^{-1}$ and those from fertilizer $\mathrm{N}$ input (1.5\% of applied $\mathrm{N}$ ) are $1.8 \mathrm{Tg} \mathrm{N} \mathrm{yr}^{-1}$. This exceeds the EDGAR estimate for $\mathrm{NO}$ from the combination of chemical fertilizer and animal wastes applied to agricultural soils. 
The 3rd International Electronic Conference on Atmospheric Sciences (ECAS 2020), 16-30 November 2020; Sciforum Electronic Conference Series, Vol. 3, 2020

Figure 4(c) shows the absolute difference between NO_STAT and EDGAR. NO_STAT gives relatively lower $\mathrm{NO}$ emission values in all areas.

The NO_STAT model provides a method for computing NO emissions using existing databases on soil, fertilizer usage, and animal waste production (Table $1 \mathrm{~b}$ ). The model also provides insight to importance of different soil parameters in producing $\mathrm{NO}$ emissions.

\section{Conclusion}

In this work, a statistical model (NO_STAT) is developed for characterizing atmospheric NO emissions from agricultural soils. As a result of only considering one source of emissions, in comparison to other data sets, the model generates a lower global NO estimates by 59\%, (NO_STAT: $0.671 \mathrm{Tg} \mathrm{N} \mathrm{yr}^{-1}$; EDGAR: 1.6 $\mathrm{Tg} \mathrm{N} \mathrm{yr}^{-1}$ ). Based on these results, NO-STAT statistical model captures the spatial distribution of global NO emissions by applying a simpler modeling approach based on existing global data sets (Table 1b). However, the model gives lower estimates compared to other inventories.

For NO_STAT, statistical model captures the spatial distribution of global $\mathrm{NO}_{x}$ emissions but the model estimate is below other model estimates and the results of literature survey. Two reasons can contribute to this underestimation. One reason is that the underestimation of $\mathrm{NO}$ emissions in comparison to EDGAR can be attributed to additional sources that EDGAR estimated, e.g. Enteric fermentation, Manure management and Rice cultivation, whereas NO_STAT is exclusive to emissions from fertilizer and manure applied as fertilizer. The other reason is that most NO field measurement campaigns are short-term and non-continuous. Since nitric oxide in the atmosphere is a precursor to tropospheric ozone, some mitigation options include reduction in $\mathrm{N}$ fertilizer use through an increase in fertilizer use efficiency, improved timing of fertilizer application, enhancing the fertilizer uptake efficiency of crops. This will have the potential to reduce global annual NO emissions.

Acknowledgments: Support for this work was provided by U.S. GFDL-NOAA project NOAA CPO AC4. We thank Dr. Larry Horowitz and Dr. Fabien Paulot both at NOAA GFDL for their ongoing discussions on the project. The authors declare no competing financial interest.

\section{Reference}

1. Akiyama, H., H. Tsuruta, and T. Watanabe (2000), N2O and NO Emissions from Soils after the Application of Different Chemical Fertilizers. Chemosphere Global Change Science, 2, 313-320. http://dx.doi.org/10.1016/S1465-9972(00)00010-6.

2. Anderson, R. C., and J. S. Levine (1987), Simultaneous field measurements of biogenic emissions of nitric oxide and nitrous oxide, J. Geophys. Res. 92(D1), 965-C976.

3. Aneja, V.P., W.P. Robarge, B.D (1995). Holbrook Measurements of nitric oxide flux from an upper coastal plain, North Carolina agricultural soil Atmospheric Environment, 29, pp:3037-3042.

4. Aneja, V.P., D.S. Kim, M. Das and B.E. Hartsell, 1996, "Measurements and analysis of reactive nitrogen species in the rural troposphere of Southeast United States: Southern Oxidant Study Site SONIA," Atmospheric Environment, Vol. 30, pp. 649-659.

5. Aneja, V. P., Paul A. Roelle and Wayne P. Robarge (1998), Characterization of biogenic nitric oxide source strength in the southeast United States Environmental Pollution 102, S1211-218.

6. Aneja, V. P., W. P. Robarge, L. Sullivan, T. Moore, T Pierce, C D. Geron, and B. Gay (1996). Seasonal variation of nitric oxide flux from agricultural soils in the Southeast United States, TELLUS 48B:626-640.

7. Aneja, V.P., W.H. Schlesinger, and J.W. Erisman, 2008, “Farming pollution," Nature Geoscience, vol. 1, pp. 409-411. http://www.nature.com/ngeo/journal/v1/n7/full/ngeo236.html.

8. Aneja, V.P., W.H. Schlesinger, and J.W. Erisman, 2009, "Effects of Agriculture upon the Air Quality and Climate: Research, Policy and Regulations," Environmental Science and Technology, vol. 43, pp. 4234-4240.

9. Aneja, V.P., W.H. Schlesinger, Q. Li, A. Nahas, and W.H. Battye, 2019. "Characterization of atmospheric nitrous oxide emissions from global agricultural soils", SN Appl. Sci. (2019) 1: 1662. https://doi.org/10.1007/s42452-019-1688-5 
The 3rd International Electronic Conference on Atmospheric Sciences (ECAS 2020), 16-30 November 2020;

Sciforum Electronic Conference Series, Vol. 3, 2020

10. Aneja, V.P., W.H. Schlesinger, Q. Li, A. Nahas, and W.H. Battye, 2020. "Characterization of the Global Sources of Atmospheric Ammonia from Agricultural Soils", Journal of Geophysical Research Atmospheres, https://doi.org/10.1029/2019JD031684

11. Battye, W., V.P. Aneja, and W.H. Schlesinger, 2017, “Is Nitrogen the Next Carbon?” Earth's Future, 5, pp. 894-904. doi:10.1002/2017EF000592.

12. Bray, C.D., W. Battye, and V. P. Aneja. 2019. "The role of biomass burning agricultural emissions in the Indo-Gangetic Plains on the air quality in New Delhi, India," Atmospheric Environment, vol. 218, pp. 116983-116991. https://doi.org/10.1016/j.atmosenv.2019.116983

13. Cheng W, Nakajima Y, Sudo S, Akiyama H, Tsuruta H (2002) N2O and NO emissions from a field of Chinese cabbage as influenced by band application of urea or controlled-release urea fertilizers. Nutrient Cycling in Agroecosystems, 63, 231-238.

14. Davidson E, Kingerlee W (1997) A global inventory of nitric oxide emissions from soils. Nutrient Cycling in Agroecosystems, 48, 37-50.

15. Galbally et al., (1987) I.E. Galbally, J.R. Freney, W.A. Muirhead, J.R. Simpson, A.C.F. Trevitt, P.M. Chalk, Emission of nitrogen oxides (NOx) from a flooded soil fertilized with urea: relation to other nitrogen loss processes, J. atmos. Chem., 5, pp. 343-365

(C) 2020 by the authors. Submitted for possible open access publication under the terms and conditions of the Creative Commons Attribution (CC BY) license (http://creativecommons.org/licenses/by/4.0/). 